\title{
Assessing the efficacy of controlled atmosphere temperature treatment system (CATTS) against codling moth inside harvested apples
}

\author{
Lisa E. Jamieson*, Reuben T. Wilkinson, Natalie E.M. Page-Weir, Amanada J. \\ Hawthorne, Domonic E. Hartnett, Simon P. Redpath, Asha Chhagan, Allan B. \\ Woolf, Agam Nangul and Lindy F. Guo \\ The New Zealand Institute for Plant \& Food Research Limited (PFR), Private Bag 92169, \\ Auckland Mail Centre, Auckland, 1142, New Zealand \\ *Corresponding author: Lisa.Jamieson@plantandfood.co.nz
}

\begin{abstract}
The controlled atmosphere temperature treatment system (CATTS) was assessed as a disinfestation tool to control codling moth (CM; Cydia pomonella) larvae inside apples. Codling moth mortality and apple quality were assessed after exposure to one of 10 treatments, which were combinations of five variables, namely, $\mathrm{O}_{2}$ concentration (air $20.9 \%, 1,2$ or $3 \%$ ); $\mathrm{CO}_{2}$ concentrations (air $0.04 \%$ or $15 \%$ ); 12 or $24^{\circ} \mathrm{C} / \mathrm{h}$ ramp rate up to $46^{\circ} \mathrm{C}$; air speed $1.3 \mathrm{~m} / \mathrm{s}$; and either 2.5 - or 3 -h treatment time. CATTS treatments resulted in higher CM mortality than equivalent hot air treatments. The treatments involving 1 or $2 \%$ $\mathrm{O}_{2}$ combined with $15 \% \mathrm{CO}_{2}$ and a ramp of $12^{\circ} \mathrm{C} / \mathrm{h}$ or $24^{\circ} \mathrm{C} / \mathrm{h}$ to $46^{\circ} \mathrm{C}$, with a total treatment time of $3 \mathrm{~h}$ or $2.5 \mathrm{~h}$ and a $1.3 \mathrm{~m} / \mathrm{s}$ air speed resulted in $100 \%$ mortality of CM. However, all CATTS and hot air treatments compromised apple quality. High CM mortality can be achieved using CATTS, but refinement of the protocol is needed to improve fruit quality outcomes.
\end{abstract}

Keywords codling moth, controlled atmosphere temperature treatment, apple

\section{INTRODUCTION}

Codling moth (Cydia pomonella (Lepidoptera: Tortricidae; CM)) is a key pest of apples exported from New Zealand. Market access for New Zealand apples into countries with strict codling moth quarantine regulations currently relies on fumigation with methyl bromide combined with cold treatment or the use of a rigorous systems approach (e.g. Taiwan). Methyl bromide is subject to phase-out requirements of the 1987 Montreal Protocol on Ozone Depleting Substances (UNEP 1987); therefore, alternative methods of disinfestation must be investigated to ensure future quarantine requirements are met.

The Controlled Atmosphere Temperature Treatment System (CATTS) was first described by Neven and Mitcham (1996) as a novel tool for postharvest disinfestation of fresh agricultural produce. Their study demonstrated the potential effectiveness of the treatment, which combined heat $\left(45\right.$ and $\left.47^{\circ} \mathrm{C}\right)$ with a controlled atmosphere (CA) of $1 \%$ oxygen $\left(\mathrm{O}_{2}\right)$ and $15 \%$ carbon dioxide $\left(\mathrm{CO}_{2}\right)$, to control CM in sweet cherries. CATTS treatments targeting CM were also developed for peaches, nectarines and apples using a target temperature of $46^{\circ} \mathrm{C}$ and a CA of $1 \% \mathrm{O}_{2}$ and $15 \% \mathrm{CO}_{2}$ (Neven et al. 2006, Neven \& RehfieldRay 2006). A CATTS treatment $\left(1 \% \mathrm{O}_{2}, 15 \%\right.$ $\mathrm{CO}_{2}$, target air temperature $46^{\circ} \mathrm{C}$ ) developed for apples grown in Washington State, USA involved a heating rate of $12^{\circ} \mathrm{C} / \mathrm{h}$, which meant the treatment time was $3 \mathrm{~h}$ (from establishment of atmosphere/start of temperature ramp to target air temperature of $46^{\circ} \mathrm{C}$ ). Apple core temperature 
reached $44.6^{\circ} \mathrm{C}$ and remained there for $15 \mathrm{~min}$, air speed was between 1.3 and $2 \mathrm{~m} / \mathrm{s}$, and humidity was $>90 \%$ (Neven \& Rehfield-Ray 2006).

Previous studies of fruit quality following CATTS treatments have shown the commodities tested were not adversely affected and all market standards were met (Neven \& Drake 2000; Neven et al. 2001; Shellie et al. 2001; Neven 2005).

The research reported here tested the efficacy of the published CATTS apple protocol, based on Neven and Rehfield-Ray (2006), against fourthinstar CM larvae in New Zealand-grown apples. Neven and Rehfield-Ray (2006) identified fourthinstar $\mathrm{CM}$ as being the life stage most tolerant to CATTS treatments. A CA treatment of $1 \% \mathrm{O}_{2}$ is difficult to achieve commercially so the effect of higher $\mathrm{O}_{2}$ concentrations on CM mortality was also tested. In addition, the effect of the CATTS parameters outlined previously on the quality of two locally grown New Zealand apple cultivars was measured. The final aim was to determine the impact of shorter treatments and a faster ramp time on both CM mortality and apple quality.

\section{MATERIALS AND METHODS}

\section{Establishment of codling moth}

Codling moth larvae were provided from a laboratory colony reared on Brinton's artificial diet (Brinton et al. 1969) at the Insect Rearing Unit of Plant \& Food Research (PFR), Auckland. Sets of thirty late third-instar CM larvae were placed onto six mature insecticide-free 'Fuji' apples within a fine mesh bag held on a large plastic tray. Each mesh bag was securely closed with a twist tie and placed at $20^{\circ} \mathrm{C}, 16$ :8h (light:dark) for $48-$ $72 \mathrm{~h}$ to allow the larvae to burrow into the fruit. During this time, larvae moulted to fourth instar.

On the morning of treatment, the bags were opened and any larvae on the surface of the fruit were removed. These larvae were counted and subtracted from the initial number (30) to give the final number of larvae, within apples, undergoing CATTS treatment per replicate. Most apples had obvious frass on the surface from larvae that had tunnelled into the fruit. In a preliminary trial, apples were assessed destructively at this stage and larvae were found throughout the apples, including at the core. In the main trial, all intact apples $(\approx 100 \%$ infested) were then loaded into net bags with larger mesh, securely closed with a twist tie and tagged with a bag number, date and treatment. Bags were used during treatment in order to ensure recovery of $\mathrm{CM}$, which sometimes exited the fruit during treatment.

Treatments are detailed in Table 1 and hereafter referred to as $\mathrm{T}$ (i.e. Treatment 1 (T1), Treatment 2 (T2) etc.). Each treatment was replicated three times. After treatment, all fruit was returned to $20^{\circ} \mathrm{C}, 16: 8 \mathrm{~h}$ (light:dark) until assessment the following day.

\section{Fruit details}

The cultivars selected for this trial were 'Fuji' and 'Scilate'/Envy" since they are commercially important varieties for Asian markets.

'Fuji' and 'Scilate'/Envy were harvested in Hawkes Bay on 8 April 2017 and 18 April 2017, respectively and were shipped via overnight refrigerated courier to PFR, Auckland. On arrival the fruit was held at $0.5^{\circ} \mathrm{C}$ for a further 11-18 weeks before treatment. On the day before treatment, 100 fruit-quality apples of each cultivar were removed from the cool store and placed at $22^{\circ} \mathrm{C}$ to warm before treatment. Insecticide-free 'Fuji' apples were also used as filler fruit.

\section{Controlled Atmosphere Temperature Treatment System (CATTS) Treatments}

CATTS and hot-air treatments were applied within the Surefruit unit at PFR, Auckland. The Surefruit unit was a purpose-built treatment facility, originally built for disinfestation treatments using heat and volatiles. The unit was approximately $2-\mathrm{m}$ high $\times 3-\mathrm{m}$ long. The treatment chamber measured $990 \mathrm{w}$ x $550 \mathrm{~h}$ x 590 $\mathrm{d}(\mathrm{mm})$ and contained eight 'treatment' plastic coated metal-mesh baskets (two columns of four layers).

Atmospheric variables (temperature, airspeed, humidity, $\mathrm{O}_{2}, \mathrm{CO}_{2}$ ) were controllable via a computer using a purpose-built LabVIEW program. Temperature was measured within 
Table 1 Parameters of Controlled Atmosphere Temperature Treatment System (CATTS) and hot air only treatments tested. Treatment duration was based on the time after controlled atmosphere (CA) establishment. The air-temperature target was $46^{\circ} \mathrm{C}$ for all treatments.

\begin{tabular}{lllll}
\hline $\begin{array}{l}\text { Treatment } \\
\text { number }(\mathrm{T})\end{array}$ & $\mathrm{O}_{2}$ target (\%) & $\mathrm{CO}_{2}$ target $(\%)$ & $\begin{array}{l}\text { Heat ramp } \\
\left({ }^{\circ} \mathrm{C} / \mathrm{h}\right)\end{array}$ & Duration $(\mathrm{h})$ \\
\hline $1^{\mathrm{a}}$ & 1 & 15 & 12 & 3.0 \\
2 & 2 & 15 & 12 & 3.0 \\
3 & 3 & 15 & 12 & 3.0 \\
4 (hot air) $^{\mathrm{b}}$ & $\sim 20.9$ & $\sim 0.04$ & 12 & 3.0 \\
5 & 3 & 15 & 12 & 2.5 \\
6 (hot air) $^{\mathrm{b}}$ & $\sim 20.9$ & $\sim 0.04$ & 12 & 2.5 \\
7 & 3 & 15 & 24 & 2.5 \\
8 (hot air) $^{\mathrm{b}}$ & $\sim 20.9$ & $\sim 0.04$ & 24 & 2.5 \\
9 & 2 & 15 & 12 & 2.5 \\
10 & 2 & 15 & 24 & 2.5 \\
\hline
\end{tabular}

${ }^{a}$ Published protocol of Neven \& Rehfield-Ray 2006

${ }^{\mathrm{b}} \mathrm{O}_{2}$ set at specified value but $\mathrm{CO}_{2}$ not controlled in these treatments

the chamber and could be increased or decreased using heating elements and a cooling unit. Airspeed was measured using an anemometer and was controlled using a centrifugal fan, capable of reaching air-speeds of $>2 \mathrm{~m} / \mathrm{s}$. Louvres controlled by compressed air allowed for the air flow direction to be changed during treatment, mitigating "cold spots" within the treatment chamber. All treatments were conducted at $101 \mathrm{kPa}$.

Relative humidity $(\mathrm{RH})$ was measured using a wet-dry bulb, and could be increased using a steam generator or decreased using a dehumidifier. The concentration of $\mathrm{O}_{2}$ and $\mathrm{CO}_{2}$ concentration was monitored using an external $\mathrm{O}_{2} / \mathrm{CO}_{2}$ monitor (Quantek Instruments Inc., Model 902P $\mathrm{O}_{2} /$ $\mathrm{CO}_{2}$ Analyzer). The oxygen concentration was decreased by controlling the flow of nitrogen $\left(\mathrm{N}_{2}\right)$ into the chamber. Nitrogen and $\mathrm{CO}_{2}$ gas were plumbed into the chamber via mass flow controllers, allowing for rapid changes in atmosphere using high flow rates, or maintenance of a particular atmosphere using trickle flow rates.

Codling moth infested 'Fuji' apples as well as uninfested export-quality 'Fuji' and 'Scilate'/Envy ${ }^{\text {rm }}$ apples were subjected to ten different CATTS and hot-air treatments (Table 1). Treatments began on 3 July 2017 and were conducted three days per week for 5 weeks, ending on 2 August 2017. Two treatments were conducted each day, one in the morning and one in the afternoon. For each day of treatments, an equivalent number of control fruit was placed in the same room as the Surefruit unit but remained at atmospheric temperature/ conditions.

Eight baskets each containing 35 apples were loaded for each run. The central four baskets contained six CM-infested 'Fuji' apples, 16 fruitquality apples ('Fuji' and 'Scilate'/Envy apples), and 13 filler apples ('Fuji'). The two top and two bottom baskets contained 34 fruit quality apples and one filler apple.

Air and apple surface temperatures were measured in all baskets and apple core temperature was measured in the central four baskets. Surface probes were attached to filler fruit using masking tape and core probes were inserted in to the apple until the end of the probe reached the core. Air probes were placed within the centre of each basket. The chamber was then sealed and the main door of the unit locked. 
For each CATTS run, the desired atmosphere was achieved using the manual control menu in the LabVIEW software before starting the automatic temperature ramp. Nitrogen was injected into the chamber at maximum flow until the $\mathrm{O}_{2}$ level was near to the desired target. The $\mathrm{N}_{2}$ flow was then decreased and $\mathrm{CO}_{2}$ was injected at maximum flow. Once $\mathrm{CO}_{2}$ reached $14.5 \%$, flow was decreased and the manual control mode was exited. This process took between 45 and $60 \mathrm{~min}$ depending on the $\mathrm{O}_{2}$ target.

Once the desired gas profile was achieved, the automatic heating ramp regime was started and this regime automatically controlled temperature, air-speed and $\mathrm{RH}$. However, the $\mathrm{O}_{2}$ and $\mathrm{CO}_{2}$ levels were maintained by constant monitoring and manual adjustment of the $\mathrm{N}_{2}$ and $\mathrm{CO}_{2}$ flows. Run time was measured from the beginning of the automatic temperature ramp.

Once the run had finished, the chamber was purged with compressed air and cooled using the internal cooling system. The purging process took approximately $30 \mathrm{~min}$ to achieve atmospheric levels of $\mathrm{O}_{2}$, during which time the chamber had cooled to approximately $25^{\circ} \mathrm{C}$.

For hot-air runs, the automatic regime was started immediately after loading and sealing the chamber. The $\mathrm{O}_{2}$ was set to $20.9 \%$ and gas inputs were disabled before the run. During the run, $\mathrm{O}_{2}$ levels would decrease slightly and $\mathrm{CO}_{2}$ levels increased due to fruit respiration. This change in gas profile was not controlled.

The apples were then unloaded from the chambers. Fruit for quality assessment were loaded into apple boxes and stored at $0.5^{\circ} \mathrm{C}$ in a cool store. The CM-infested apples were loaded onto plastic trays and returned to the $20^{\circ} \mathrm{C}$ controlled temperature room overnight, for assessment the following day.

\section{Insect mortality assessments}

Codling moths present inside and outside apples were assessed the day after treatment. The presence of CM outside apples after treatment is consistent with observations of CM exiting fruit during CATTS treatment in the USA (L. Neven, pers. comm.). Apples were cut open to retrieve $\mathrm{CM}$ for life-stage assessment. Larvae were found throughout the fruit, including in the core. Larvae were assessed as live (= movement when prodded with blunt forceps), dead (= discoloured, no movement), or moribund (= discoloured, little movement).

\section{Fruit quality assessments}

Following treatment, fruit destined for quality assessments were repacked in boxes and returned to $0.5^{\circ} \mathrm{C}$ for 8 weeks. Fruit from each treatment was packed in two boxes: one 80 -count apple box ( 80 fruit/box) using four 20 -count trays, and one large kiwifruit box to store the additional 20 fruit. No polythene liners were used. Following storage, the fruit were moved to $20^{\circ} \mathrm{C}$ for 7 days to simulate shelf life before fruit quality was assessed.

Fruit were externally assessed for rots and heat damage (browning and discolouration), followed by cutting the fruit for assessment of internal rots. Only external rot data are reported here as any external rot is commercially unacceptable.

A subsample of fruit exhibiting rots was selected, and isolations made from rots to identify the causal organism.

\section{Statistical analyses}

Data analyses were conducted using SAS software version 9.4 (SAS Inc., USA). The mortality of CM (dead/total post-treatment) was analysed based on a binomial model adjusted for over dispersion and rare event. Logistic regression (proc logistic) was used to fit binomial models, "scale $=$ deviance" was used to adjust for over-dispersion and "firth" correction was used to adjust for rare events. Analysis was not conducted on fruit quality data due to the overall poor fruit quality across all treatments.

\section{RESULTS}

\section{Insect mortality}

The treatment closest to the published CATTS protocol for CM on apples (T1) resulted in 100\% mortality of New Zealand CM. Increasing the $\mathrm{O}_{2}$ concentration to $2 \%$ or $3 \%$ (T2 and T3) resulted in $100 \%$ and $99.6 \%$ mortality, respectively. These 
three treatments were not significantly different from each other (Fig. 1) at the 5\% significance level. However, treatments with less than $100 \%$ mortality are unlikely to be accepted by overseas markets. Codling moth mortality was higher in each of these 3-h CATTS treatments compared with an equivalent hot-air only treatment (i.e. no CA atmosphere) where only $65.4 \%$ of CM were killed. Poor fruit quality was observed following the use of the 3-h long treatments so the duration of the CATTS treatment was reduced to $2.5 \mathrm{~h}$ (T9 and T5). The shorter run time resulted in reduced mortality rates $\left(92.5 \%\right.$ after a $2 \% \mathrm{O}_{2}$ treatment (T9) and $64.4 \%$ mortality after a $3 \% \mathrm{O}_{2}$ treatment (T5); Fig. 1) but did not rectify the fruit-quality issues. Only $15.4 \%$ of $\mathrm{CM}$ were killed by the equivalent hot-air only treatment (T6).

Finally, a faster ramp rate $\left(24^{\circ} \mathrm{C} / \mathrm{h}\right)$ was tested with a total duration of $2.5 \mathrm{~h}$, to determine the impact of ramp time on CM mortality. These treatments resulted in CM mortality of 100 or $97.1 \%$ after exposure to a 2 or $3 \% \mathrm{O}_{2}$ treatment

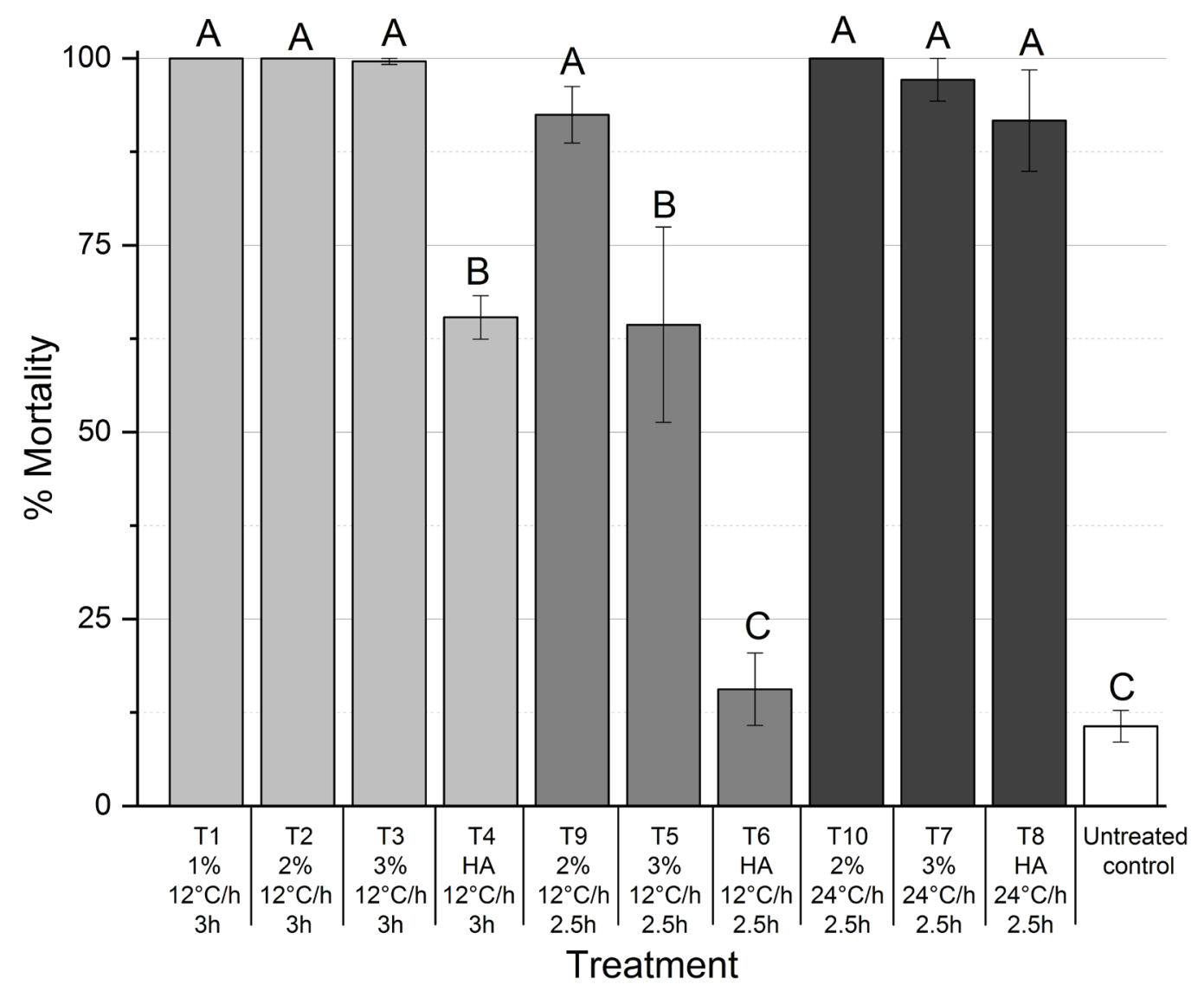

Figure 1 Mean percentage mortality of fourth-instar codling moth larvae in 'Fuji' apples following Controlled Atmosphere Temperature Treatment System (CATTS) and hot air (HA) treatment and an untreated control. Treatment conditions are specified as follows: row 1 - treatment number; row 2 oxygen concentration or HA; row 3 - ramp speed; row 4 - trial duration. Letters in common above bars $(\mathrm{A}, \mathrm{B}, \mathrm{C})$ indicate no statistical difference between treatments. Bars are coloured according to the heat ramp and duration of treatments: $12^{\circ} \mathrm{C} / \mathrm{h}+3 \mathrm{~h}$ (light grey), $12^{\circ} \mathrm{C} / \mathrm{h}+2.5 \mathrm{~h}$ (grey) and $24^{\circ} \mathrm{C} / \mathrm{h}+2.5 \mathrm{~h}$ (dark grey). 
(T10 or T7 respectively). The difference in mortality between the CATTS $(100 \%$, T10; $97.1 \%, \mathrm{~T} 7)$ and the hot air $(91.7 \%, \mathrm{~T} 8)$ treatments using these faster ramp rates was less than the difference between CM mortalities after CATTS treatments and hot-air treatment with slower temperature ramp rates (Fig. 1).

Overall, CATTS treatments were more effective at controlling CM larvae in apples than the corresponding hot-air only treatments. Codling moth mortality increased when $\mathrm{O}_{2}$ concentration decreased, and ramp rate or duration increased.

For the shorter duration treatments $(2.5 \mathrm{~h})$ with $12^{\circ} \mathrm{C} / \mathrm{h}$ ramps (i.e. T5, T6, T9), a target core temperature of $\geq 44.6^{\circ} \mathrm{C}$ was achieved for an average duration of $17 \mathrm{~min}$ compared to treatments with faster ramps $\left(24^{\circ} \mathrm{C} / \mathrm{h}\right.$, i.e. T7, T8,
T10) or longer treatment times ( 3 h, i.e. T1, T2, $\mathrm{T} 3, \mathrm{~T} 4)$ that achieved core target temperatures for an average duration of $50 \mathrm{~min}$.

\section{Fruit quality}

All CATTS treatments, including hot air alone, resulted in a high incidence of rots (Fig. 2) and external browning for all cultivars and treatments, following 8 weeks cool storage at $0.5^{\circ} \mathrm{C}$ and 7 days simulated shelf life at $20^{\circ} \mathrm{C}$. There was little difference between the two cultivars. A subsample of 10 fruit from each treatment group were cut transversally to assess internal damage. All of these fruit displayed severe external and internal damage. Organisms associated with rots that were isolated were identified as Phomopsis sp., Neofabraea alba, and Alternaria sp.

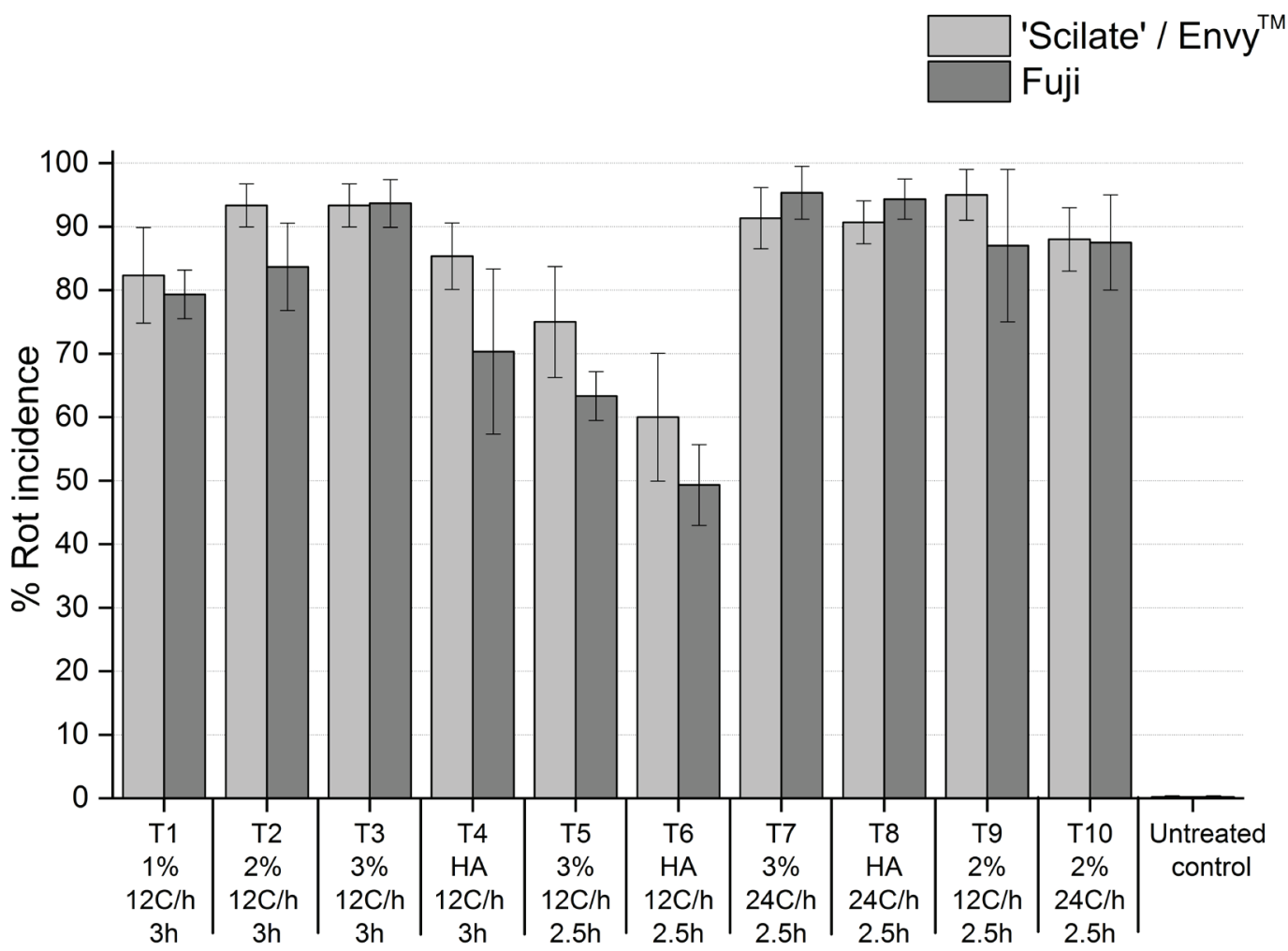

Figure 2 Mean incidence of external rots/soft spots of fruit treated in the Controlled Atmosphere Temperature Treatment system (CATTS), or with hot air (HA) alone, after 8 weeks cool storage at $0.5^{\circ} \mathrm{C}$ and $7 \mathrm{~d}$ simulated shelf life at $20^{\circ} \mathrm{C}$. Treatment conditions are specified as follows: row 1 - treatment number; row 2 - oxygen concentration or HA; row 3 - ramp speed; row 4 - trial duration. 
None of the CATTS or hot air alone treatments resulted in acceptable fruit quality with all treatments having less than $22 \%$ acceptable fruit after treatment (data not presented).

Untreated control fruit were assessed as $100 \%$ acceptable. Thus, both heat and CATTS treatments caused significant and unacceptable levels of damage to the fruit used in this experiment. It should be noted that the fruit had been cool-stored for a significant period before treatment (11-18 weeks). The high $\mathrm{RH}$ and condensation on fruit may have contributed to the damage observed.

\section{DISCUSSION}

The CATTS treatment T1 with the parameters closest to the apple CATTS protocol published by Neven \& Rehfield-Ray (2006) killed 100\% of CM larvae in this study, however apple quality was significantly compromised. Decreasing the treatment duration reduced CM mortality and still compromised fruit quality. Increasing the temperature ramp rate combined with a shorter treatment time maintained high CM mortality, but fruit quality remained unacceptably poor.

Temperature conditions at the fruit core in these trials were more severe than in the published Washington State apple CATTS protocol. In these trials, average core temperatures were $\geq 44.6^{\circ} \mathrm{C}$ for 48-62 min (T1-4), whereas in Washington State apple core temperatures were $\geq 44.6^{\circ} \mathrm{C}$ for 15 m (Neven \& Rehfield-Ray 2006). However, reducing the treatment duration $(2.5 \mathrm{~h} ; \mathrm{T} 5, \mathrm{~T} 6$, T9) led to an average core temperature of $44.6^{\circ} \mathrm{C}$ for $17 \mathrm{~m}$, but reduced CM mortality and failed to provide acceptable fruit quality. The reduction in mortality for $\mathrm{T} 5$ and $\mathrm{T} 9$, may be attributable to the use of 2 or $3 \% \mathrm{O}_{2}$, not $1 \%$ as per the published protocol.

Similar trials conducted in New Zealand in 2016 used a six-chamber unit with a lower air speed but it was difficult to achieve a core temperature of $44.6^{\circ} \mathrm{C}$ in any of the treatments tested (Page-Weir et al. unpublished data). In the present trials, the upgraded Surefruit unit achieved the target core temperature sooner than intended. We recommend that future trials use a computer-controlled program that adjusts the rate of air temperature increase based on feedback from the fruit-core temperature probes.

A major contribution to poor fruit quality in this study was most likely the long storage time the fruit experienced before CATTS treatment. Such storage would have disrupted diurnal fruit temperature tolerance patterns making them more susceptible to damage resulting from the extreme heating experienced in the trials (L. Neven, USDA_ARS, personal communication). Unfortunately, fruit were cool stored before treatment for much longer than planned, due to setbacks with upgrading the Surefruit unit used for the trials.

Dew-point control and temperature ramp rate are also suspected to have contributed to issues with fruit quality (L. Neven, USDA_ ARS, personal communication). The $\mathrm{RH}$ in the chamber used in the present trials was higher than that reported by Neven and Rehfield-Ray (2006), resulting in condensation on fruit, which can lead to fruit damage. Condensation may not have occurred if the temperature differentials between the air, surface and core temperature had been controlled to below a $2^{\circ} \mathrm{C}$ differential on the coldest fruit. Alternatively, a lower $\mathrm{RH}$ could be employed, but the effect on fruit weight loss would need to be measured and compared with higher RH treatments.

The temperature ramp rates were adopted from Neven and Rehfield-Ray (2006) and may not be suitable for New Zealand cultivars of apple or growing climate. Heating ramp rates should be based on the natural heating rates of fruit that occurs while the fruit are still on the tree (L. Neven, USDA-ARS, personal communication). Heating rates and maximum temperatures experienced by New Zealand apples are most likely much lower than those in Washington State. Therefore, fruit heating ramp rates (e.g. $6^{\circ} \mathrm{C} / \mathrm{h}$ or $8^{\circ} \mathrm{C} / \mathrm{h}$ ) and maximum fruit temperature should be defined by field monitoring and trialled next season.

Additionally, Neven and Rehfield-Ray (2006) included a super-cooling phase of $0^{\circ} \mathrm{C}$ forced air cooling after CATTS treatment, which was not 
included in the current study.

Although CATTS treatments close to the published apple CATTS protocol achieved excellent CM mortality, further refinements of the CATTS parameters are required in order for New Zealand-grown apples to tolerate CATTS treatments.

\section{ACKNOWLEDGEMENTS}

The authors would like to thank Richard Oliver, James Pinfold, Ian Visagie (PFR Ruakura), Bruce Freeth (PFR Auckland) and Mark Roche (Technolutions Ltd) for engineering and programming work on the Surefruit unit; Jack Armstrong (Quarantine Scientific Ltd) for providing a comprehensive review of CATTS; Dave Rogers, Lyn Cole (PFR Hastings) and Duncan Park (T\&G Global Limited) for the supply of apples; Anne Barrington, Sophie Hunt, Pauline Boxen and Su Corrin (PFR Auckland) for supply of codling moth larvae. The authors are grateful to Kerry Everett and Shamini Pushparajah (PFR) for isolating and identifying pathogens associated with rots; Lisa Neven (USDA-ARS) for post-trial discussions; Peter Lo and Samuel Brown (PFR Hastings and Auckland) for valuable comments on this manuscript. This research was funded by New Zealand Apple and Pears Inc. and MBIE under the Apple Futures II programme.

\section{REFERENCES}

Brinton FE, Proverbs MD, Carty BE 1969. Artificial diet for mass production of the codling moth Carpocapsa pomonella (Lepidoptera: Olethreutidae). The Canadian Entomologist 101(6): 577-584.

Neven L, Mitcham E 1996. CATTS (Controlled Atmosphere/Temperature Treatment System): A novel tool for the development of quarantine treatments. American Entomologist 42(1): 56-59.

Neven LG, Drake SR, Shellie KC 2001. Development of a high temperature controlled atmosphere quarantine treatment for pome and stone fruits. Acta Horticulturae 553 (2): 457-460.
Neven L 2005. Combined heat and controlled atmosphere quarantine treatments for control of codling moth in sweet cherries. Journal of Economic Entomology 98(3): 709-715.

Neven LG, Drake SR 2000. Comparison of alternative postharvest quarantine treatments for sweet cherries. Postharvest Biology and Technology 20(2): 107-114.

Neven L, Rehfield-Ray L 2006. Confirmation and efficacy tests against codling moth and oriental fruit moth in apples using combination heat and controlled atmosphere treatments. Journal of Economic Entomology 99(5): 1620-1627.

Neven L, Rehfield-Ray L, Obenland D 2006. Confirmation and efficacy tests against codling moth and oriental fruit moth in peaches and nectarines using combination heat and controlled atmosphere treatments. Journal of Economic Entomology 99(5): 1610-1619.

Shellie K, Neven, LG, Drake, SR 2001. Assessing 'Bing' sweet cherry tolerance to a heated controlled atmosphere for insect pest control. HortTechnology 11(2): 308-311.

UNEP 1987. Montreal protocol on substances that deplete the ozone layer United Nations Environment Programme. Published by Secretariat for The Vienna Convention for the Protection of the Ozone Layer \& The Montreal Protocol on Substances that Deplete the Ozone Layer, United Nations Environment Programme, Nairobi, Kenya http://www.unep.org/ozone 